\title{
Explorando el Potencial Pedagógico del Relato Digital en un Contexto Nicaragüense
}

Nahúm Tórrez ${ }^{1}$

\section{RESUMEN}

El presente estudio tuvo como principal objetivo explorar el potencial pedagógico del método del Relato Digital en un contexto nicaragüense. Por tal razón, en éste se presentó el origen de los conceptos relato digital y texto pedagógico. Adicionalmente, se investigó el punto de vista de diesiciete estudiantes de Ciencias de la Educación, de la Facultad Regional Multidisciplinaria de Estelí (UNAN- FAREM- Estelí) sobre el valor pedagógico del relato digital en sus propios centros de trabajo, con sus propios estudiantes. Con el objetivo de presentar el método del relato digital a estudiantes nicaragüenses, se implementó un taller de relato digital en uno de los laboratorios de la facultad. Así mismo, se aplicó un cuestionario para obtener el punto de vista de los participantes sobre esta forma de contar historias como texto pedagógico. Los principales resultados muestran que los estudiantes si ven un potencial real en este método como una herramienta educativa, $\mathrm{y}$ también que lo consideran como algo innovador en su quehacer educativo.

Palabras claves: Relato digital, digital storytelling y texto pedagógico

Recibido: 18 de septiembre de 2015

Aceptado: 02 de octubre de 2015

1 Docente de Inglés y Educación Infantil en UNAN- FAREM, Estelí; Máster en textos pedagógicos del Colegio Universitario de Buskerud Vestfold, Noruega. Campos de interés: Aprendizaje y enseñanza de lenguajes extranjeros, estudio de libros ilustrados, semiótica social, multimodalidad, alfabetismo y alfabetismo digital. Correo electrónico: nahtorrez@gmail.com 


\section{Exploring the educational potential of the Digital Story in a Nicaraguan Context}

\section{SUMARY}

This study has as main objective to explore the educational potential of the digital story method in a Nicaraguan context. For this reason, in this study the origin of the digital story concepts and pedagogical text were presented. In addition, the perception of seventeen students of Educational Sciences, of the Regional Multidisciplinary Faculty Estelí (UNAN- FAREM- Estelí) about the educational value of digital story in their own workplaces, with their own students was investigated. In order to present the method of digital story to Nicaraguan students, a digital story workshop was implemented, in one of the laboratories of the faculty. Also, a questionnaire was applied to obtain the point of view of the participants about this form of telling stories as a teaching text. The main results show that students see a real potential in this method as an educational tool, and also they see it as something innovative in their educational performance.

Keywords: digital, digital storytelling and educational text Story 


\section{INTRODUCCIÓN}

Mi primer encuentro con el relato digital ${ }^{1}$, en agosto del 2012, me causó una gran impresión. Fue en la biblioteca del Colegio Universitario de Vestfold en Noruega, donde junto con mis compañeros del modulo tres del Máster en textos pedagógicos, asistí a una conferencia sobre relato digital y sus posibles fines educativos. Observamos algunos relatos producidos por estudiantes noruegos sobre temas diversos, desde experiencias personales hasta información geográfica. Desde ese momento, decidí profundizar en el estudio de este tipo de relato y supe que queria desarrollar un estudio de tésis sobre este recurso.

El relato digital es un concepto internacional (Høiland \& Wølner, 2007). Este concepto consiste en combinar el arte tradicional de contar historias o relatos con algunas de las herramientas digitales existentes en tiempos modernos (Bernard, 2008). El uso del relato digital ha sido objeto de estudio en varios países; sin embargo, la mayoría de las investigaciones se han enfocado en "actividades fuera de la escuela, por ejemplo, actividades relacionadas a programas después extra-curriculares" (Silseth \& Erstad, 2012, p. 232).

A pesar de que el método del relato digital ha sido investigadomayormente en actividades extra- escolares, como se mencionó anteriormente, algunos académicos si han tratado de explorar el varlor educativo de este tipo de narración de historias (Por ejemplo Baltzersen, 2012, Bernard, 2012; Haug, Jamissen \& Ohlmann, 2012; Sadik, 2008, etc.). Basandome e inspirándome en algunos de sus estudios, decidí profundizar en el estudio del relado digital y explorar su protencial pedagógico en un contexto nicaragüense.

Las preguntas centrales en este estudio fueron: a) ¿Qué es el relato digital y qué hace de éste método algo más

1 El término relato digital es la traducción en español del término digital storytelling. Este término puede hacer referencia al proceso de producción de un relato, o al producto de este proceso (Baltzersen, 2012). que la simple producción de un video ordinario? b) ¿Qué elementos toman en cuenta los productores de relatos digitales para crear sus textos? Y c) ¿Cómo valora un grupo de estudiantes de la FAREM, Estelí al relato digital como texto pedagógico en su propio quehacer educativo?

\section{MARCO TEÓRICO CONCEPTUAL}

El principal objetivo de este estudio fue explorar el valor pedagógico del método del Relato Digital como Texto Pedagógico, como se mencionó anteriormente. Por tanto, este presentó una conceptualización de los términos relato digital y texto pedagógico. Teniendo un cuadro general sobre en qué consiste un relato digital, los tipos de relatos existentes, etc., así como las características del texto pedagógico, se pudo analizar si un relato digital puede considerarse como pedagógico o no.

\section{Videos Digitales y Relato Digital}

El término video digital puede sugerir una variedad de significados para personas diferentes. Como un concepto general, se puede decir que "todas las historias producidas con la ayuda de medios digitales; por ejemplo video juegos, presentaciones en Power Point, etc.", pueden ser considerados como un video digital (Haug, Jamisen \& Ohlman, 2012, p. 14), Bernard (2008) concuerda con este concepto y dice que la acción de "combinar el arte eterno de contar historias junto con cualquier variedad de herramientas de multimedia como gráficos, audio, animación, etc" puede ser considerado como un video digital (p. $3^{2}$ ). Sin embargo, existe el término relato digital.

El relato digital es considerado como un método donde el enfoque es la producción y el compartimiento de un relato basado la mayoria de las veces en una memoria o experiencia personal (Normann, 2011). Hay millones

2 Tanto esta como el resto de citas directas han sido traducidas por mí mismo (noruego/sueco/español/inglés-español). Por tanto, tomo la total responsabilidad de sus contenidos. 
de videos creados con diferentes objetivos. Muchos podrian defender la idea de que el relato digital no es más que un nuevo nombre para la práctica ya establecida de crear peliculas cortas. No obstante, no todo video puede considerarse como el resultado de la aplicación de los métodos para un relato digital.

Para poner un ejemplo, se puede pensar en un video tutorial que se puede encontrar en sitios como YouTube, quizás uno que contenga una lección de guitarra para aprender a tocar una canción de los Beatles $^{3}$. Aunque claramente éste es un video digital y algún tipo de narración es contenida en el mismo, no se puede considerar como el producto de un relato producido mediante la aplicación del método del relato digital. ¿Qué es entonces un relato digital y que hace de este concepto algo más que la simple creación de un video ordinario? Para responder a esa pregunta clave, me propongo discutir el origen del concepto y sus implicaciones.

\section{Origen del Concepto de Relato Digital}

El concepto de relato digital fue primariamente desarrollado en el Centro de Relato Digital en California, en los años 90 (Baltzersen, 2012; Haug et al., 2012). Las tecnologías emergentes de ese tiempo ofrecían nuevas herramientas de expresión y experimentación. Dana Atchley, un productor de media y artista disciplinario, junto con Joe Lambert, un productor de teatro local, descubrieron que algunas personas con poca o nula experiencia en multimedia podrian producir relatos personales poderosos con esa tecnología existente en ese entonces.

En 1994, Lambert y Achtley, junto con Nina Mullen, fundaron el Centro de Media en San Francisco, donde ellos enseñaron herramientas de relato digital. En 1998, éste centro se mudó a Berkeley y llegó a ser el Centro de Relato Digital ${ }^{4}$ (Baltzersen, 2012). Dentro

3 Vease por ejemplo http://www.youtube.com/watch?v=a31v0B$7 \mathrm{~N} 2 \mathrm{fA}$

4 http://www.storycenter.org/ de esta tradición un relato digital es una historia corta, usualmente no más larga de cinco minutos donde el productor utiliza su própia voz al contar su própia historia. Los temas para un relato digital pueden contener desde reflexiones personales a asuntos instructivos; sin embargo, sin importar el tema en el relato, éste tendra un carácter personal puesto que el que escribe la historia es el mismo que la cuenta durante el proceso de producción (Baltzersen, 2012; Haug et al., 2012). El relato digital describe entonces el o los procesos mediante el cuál gente ordinaria y no expertos en media utilizan herramientas digitales con el fin de crear narrativas personales para una variedad de propósitos.

ElCentro de Relato Digital en California ha desarrollado siete elementos que nos ayudan a diferenciar al relato digital de otro tipo de relatos o producción de videos. Lambert (2010) explica que un relato digital debe contener un punto de vista; es decir, un propósito, un mensaje que se necesita dar a conocer. Además, éste debe tener una pregunta dramática. Esto se refiere a una pregunta clave que capte la atención del receptor y que sea claramente respondida al final del relato. Otro elemento importante es el contenido emocional en este tipo de relatos. Esto se puede lograr mediante imágenes, efectos de sonidos, música y por supuesto la voz del creador de modo que se pueda transmitir emociones en la historia. La voz del autor es otro elemento de importancia. Esto representa una manera de personalizar la historia para ayudar a la audiencia a entender el contexto. Cada persona tiene una voz única y así deberia ser valorada. El poder del sonido es esencial también. El autor puede utilizar música y otros sonidos que apoyen a embellecer la historia. Estos pueden fortalecer sentimientos, crear emoción y compromiso con la historia. Un relato digital dura usualmente pocos minutos. Por tanto, es importante utilizar solamente el contenido suficiente para contar la historia sin sobrecargar al receptor. Es importante que el relato contenga solamente los elementos necesarios de modo que el receptor pueda utilizar su fantasia e 
imaginación. A esto le llaman economía, según el Centro de Relato Digital en California (Lamber, 2010). Finalmente, el relato debe contener un ritmo, el progreso rápido o lento en que se narre.

Lambert (2010) afirma que el enfoque del relato digital en todos estos años ha sido "ayudar al narrador a encontrar las historias que quieren o necesitan narrar, y guiarlos a definirlas en forma de una narrativa sólida" (p. 10). Esas historias son entonces transformadas a relatos digitales utilizando media digital. Eso significa que en el relato digital, el factor más importante es el carácter personal de cada historia y el significado para el narrador; no necesariamente cuanta habilidad digital o competencia sean visibles en el producto final.

La producción de relatos digitales ocurre usualmente en un taller de relato digital. Sin embargo, cualquier persona que estudie el proceso de producción puede crear uno desde su hogar, escuela u otro sitio. El modelo de taller que el centro en California ha desarrollado es seguido hoy en dia por muchos quienes producen relatos digitales ${ }^{5}$. Los participantes no son necesariamente expertos en la computación. Una de las metas principales para los usuarios del relato digital es la adquisición de competencias digitales y aprender como usar herramientas básicas (Næss, 2006). Se da más importancia, entonces, al aprendizaje obtenido durante el proceso de producción que al producto, el relato digital.

En los últimos años, una variedad de aplicaciones se han hecho disponibles para la creación de este tipo de relatos. Una de estas aplicaciones es Fotos Narradas 3 para Windows. Fotos Narradas es completamente gratis y permite crear videos a partir de imágenes capturadas desde una cámara digital, un telefono celular o descargas de internet. En unos simples pasos, cualquier persona puede importar y editar sus fotos una por una, insertar títulos, narrar su voz, agregar música de fondo, especificar locaciones para zooming y agregar efectos de transición (Sadik, 2008).

\section{Tipos de Relatos Digitales}

Aunque la mayoria de los relatos producidos como resultado de la aplicación del proceso del relato digital cuentan acerca de eventos importantes o momentos en la vida de una persona, es importante destacar que hay más de un tipo de relato digital. Bernard (2008) los categoriza en tres grupos: narrativas personales, relatos digitales que examinan eventos históricos y relatos que informan o instruyen (p. 224,225).

Las narrativas personales. Este tipo de relatos son producidos con el objetivo de contar una narrativa personal. El número de experiencias que pueden ser contadas por medio de éste tipo de relato es sencillamente ilimitado (Bernard, 2008). Lambert (2010) explica que cualquier experiencia en la vida de una persona puede ser el contenido para un relato digital, lo que realmente importa es el significado para el autor. El dice que "un relato puede ser tan corto como la explicación de por qué compraste tu primer coche o casa, o tan largo como la guerra y la paz. Tus própios deseos en la vida, las dificultades que has enfrentado, y más importante, la cantidad de realizaciones en tus experiencias que enriquecen tus habilidades naturales como narrador de historias" (p. 1). Este es el tipo de relato digital más común porque da la oportunidad de expresar experiencias, sentimientos y emociones.

Relatos digitales que examinan eventos históricos. Aunque muchas narrativas personales pueden incluir información histórica, un tipo diferente de relato puede ser creado a partir de material histórico que el productor quiera explorar. En un aula de clase, los estudiantes pueden utilizar fotografías históricas, encabezados de periódicos, discursos y otros materiales disponibles para formar la historia y agregar significado a los eventos del pasado.

Relatos que informan o instruyen. Este tipo de relato es usado principalmente para transmitir material instruccional en muchas áreas. Se puede argumentar que todos los relatos digitales informan (e incluso 
instruyen), pero la distinción aqui es que hay espacio para separar estos relatos en una categoria diferente. Este tipo de relatos puede contener instrucción en materias como matemáticas, ciencia, salud, tecnología, etc.

\section{Texto Pedagógico 6}

Tradicionalmente, la palabra texto se ha relacionado con expresiones materializadas en papel (Selander \& Skjelbred 2004). Cuando alguien escucha la palabra texto, seguramente se le vienen a la mente imágenes de letras o palabras. Muchas de las definiciones ofrecidas por un sin número de diccionarios para la palabra texto hacen referencia meramente a lenguaje verbal. Por ejemplo, la Real Academia Española (2015) define el término de la siguiente forma:

a. Enunciado o conjunto coherente de enunciados orales o escritos

b. Pasaje citado de una obra escrita u oral

c. Sentencia de la Sagrada Escritura

d. Todo lo que se dice en el cuerpo de la obra manuscrita o impresa, a diferencia de lo que en ella va por separado; como las portadas, las notas, los índices, etc.

e. Grado de letra de imprenta, menos gruesa que la parangona y más que la atanasia.

El concepto amplio de texto empezó a ser utilizado en los años setenta (Selander \& Skjelbred, 2004). Michael Halliday (1985) define el texto como "cualquier instancia de lenguaje viviente que está participando en un contexto". Esto quiere decir una "conversación, una grabación, una etiqueta, una señal en una puerta, o cualquier cosa que pueda ser utilizado para transmitir un mensaje. Este texto es comprendido por los miembros de la sociedad - grupo - en cuál fue creado. Y éste puede ser oral o escrito" (p. 10).

6 En éste artículo, los términos educativo y pedagógico son sinónimos. Por tanto, un relato digital pedagógico y un relato digital educativo se refieren a lo mismo.
El término texto pedagógico fue introducido por el professor sueco Staffan Selander en los años 80 en Escandinavia, especialmente en Suecia y Noruega sobre libros de texto y media educacional, y en Dinamarca como recursos de enseñanza (Knudsen \& Aamotsbakken, 2010; Selander \& Skjelbred, 2004). Selander \& Skjelbred (2004) establecen tres requisitos para que un texto pueda ser considerado como pedagógico. Estos son "intención", "contexto" y "texto" (p. 34).

La intención de un texto, tiene mucho que ver con su carácter. Knudsen y Aamotsbakken (2010) mencionan que el texto pedagógico "tiene como intención instruir a alguien en algo" (p. 19). También "estará orientado hacia información y entendimiento" (Selander \& Skjelbred 2004, p. 36). El verbo instruir conlleva la idea de informar, enseñar, aconsejar, educar, dar lecciones, preparar, etc., éste es la intención del texto pedagógico (Høiland \& Wølner, 2007). El texto pedagógico es un artefacto, un canal de conocimiento que será "adaptado" (Selander \& Skjelbred, 2004, p. 38). Con esto se entiende que éste texto será diseñado para un grupo específico de acuerdo con las caracteristicas especificas de ese grupo.

En cuanto a contexto, Halliday \& Hasan (1985) explican que "todo uso de lenguaje tiene un contexto" (p. 45). El texto pedagógico, al igual que otros textos, "obtienen su significado de su contexto" (Selander \& Skjelbred 2004, p. 36). Un texto pedagógico puede ser encontrado en un contexto de aula de clase. Esto puede ser en forma de libros de textos, discurso y conversaciones, folletos instructivos, programas de enseñanza y otros recursos que tienen como intención la facilitación del aprendizaje. Existen otros textos pedagógicos que no siguen un contexto escolar. Estos pueden ser por ejemplo el material para un curso desarrollado en una empresa, e incluso una conversación entre pacientedoctor (Selander \& Skjelbred, 2001). 
Finalmente, en lo que corresponde a texto, el texto pedagógico debe ser visto desde una perspectiva o sentido amplio, que incluye mucho más que lenguaje verbal. Investigadores como Selander y Skelbred (2004), Knudsen y Aamotsbakken (2010), Kress y van Leeuwen (2006), entre otros, han investigado las diferentes formas que un texto en sentido amplio puede abarcar.

Para ilustrar la diferencia entre un texto pedagógico o no pedagógico, podemos pensar en un carpintero que tiene un martillo. El carpintero utiliza su martillo para golpear directa o indirectamente una pieza, causando su desplazamiento o deformación. El uso más común es para clavar (incrustar un clavo de acero en madera u otro material), calzar partes (por la acción de la fuerza aplicada en el golpe que la pieza recibe) o romper una pieza. Los martillos son a menudo diseñados para un propósito especial, por lo que sus diseños son muy variados. Un tipo de martillo tiene una cuña abierta en la parte trasera para la remoción de clavos. ¿Qué sucede si un niño de cinco años utiliza el mismo martillo del carpintero para jugar? Quizas éste niño puede imaginar que el martillo es un avión, un barco o un tren, y lo utiliza para este propósito. En ese caso se puede decir que el niño utiliza el martillo con una intención diferente a la que el carpintero la utiliza o para la cuál éste instrumento fue diseñado. Lo mismo pasa con el texto pedagógico, para que pueda recibirse como pedagógico, debe ser utilizado para la intención para la cuál fue diseñado y creado ${ }^{7}$.

Un elemento importante para que un texto pueda recibirse como pedagógico es la adaptación, como se mencionó anteriormente. Se puede pensar en que un profesor de primaria utiliza un libro de matemáticas para quinto grado. Si al planificar e impartir su clase se da cuenta que los ejercicios encontrados en el libro son completamente imposibles de entender para esos

7 Ejemplo obtenido durante una conversación con la Dra. Biljiana C. Fredriksen, docente de pedagogía y arte en el Colegio Universitario de Buskerud y Vestfold, Noruega. niños, si esos ejercicios no concuerdan con la realidad del grupo o de los niños individualmente, si estos ejercicios no facilitan el aprendizaje e instruccion. En tal caso, sería difícil considerar que el profesor elegió el texto pedagógico correcto para sus niños.

\section{MATERIALES MÉTODOS}

La metodología utilizada en esta investigación siguió el diseño cualitivativo, el cuál intenta entender a profundidad las características de la situación y el significado aportado por los participantes, y lo que les está sucediendo a ellos al momento de realizar la investigación (Patton, 2002). Esta metodología constó de dos componentes principales. En primer lugar, se planificó e implementó un taller de relato digital, durante la tercera semana de octubre 2013. Dicho taller siguió las directrices e instrucciones del Centro de Relato Digital en Berkeley, California ${ }^{8}$. En el taller los estudiantes tuvieron la oportunidad de recibir instrucción sobre como redactar una historia corta, así como sobre como utilizar herramientas básicas de computación para crear narrativas digitales cortas.

En segundo lugar, se aplicó un cuestionario corto para obtener el punto de vista de ellos sobre el potencial del relato digital como texto pedagógico, y como ellos podrían utilizar este método en sus contextos pedagógicos. El cuestionario es un método de colección de información muy utilizado en la investigación cualitativa (Cresswel, 2009). Este permite obtener información relevante sobre las percepciones, actitudes, forma de pensar, etc., de los participantes de una investigación (Befring, 2007). El cuestionario les permitió a los estudiantes razonar e interpretar sobre la utilidad del método del relato digital en un contexto nicaragüense, donde las condiciones no son las más ideales para estudiantes en la producción de videos digitales, como se discutirá más adelante.

8 http://www.storycenter.org 


\section{RESULTADOS Y DISCUSIÓN}

Los resultados y su discusión serán presentados en base a las tres preguntas principales de investigación, que fueron formuladas con propósitos de este estudio.

\section{a. ¿Qué es el relato digital y qué hace de éste método algo más que la simple producción de un video ordinario?}

El Relato Digital es un metodo que permite a individuos no expertos en tecnología contar historias de forma digital (Høiland \& Wølner, 2007). Robin (2008) argumenta que se entiende como Relato Digital a "la combinación del arte de contar historias con una gran variedad de herramientas multimedias" (p. 3). De acuerdo al Centro de Relato Digital en Berkeley, California este método se diferencia entre otras producciones digitales en el enfoque utilizado por sus narradores. Lambert (2010) explica que en el enfoque de contar historias de dicho centro, lo más importante es la historia o relato en sí, no precisamente la tecnología utilizada.

\section{b. ¿Qué elementos toman en cuenta los productores de relatos digitales para crear sus textos?}

Los relatos digitales son textos multimodales; es decir, textos que están compuestos de varios recursos semióticos, por ejemplo música, lenguaje verbal e imágenes visuales (Ver Kress \& van Leeuwen, 2006).

A pesar de que los relatos digitales son textos sencillos en comparación con textos como documentales, noticieros, etc., estos crean significado mediante la combinación e interacción de diferentes recursos que el autor tiene a su alcance.

En un relato digital, el autor puede utilizar una imagen visual y, a partir de este recurso, contar la historia mediante lenguaje verbal. Así mismo, otros elementos como sonidos o canciones pueden ser agregados para crear un ambiente en el relato o simplemente para unificar los recursos semióticos y convertirlos en una unidad. Esta combinación puede tener un gran impacto en el receptor del texto, pues como menciona Engelstad (2008), los textos multimodales nos exponen e influyen varios de nuestros sentidos a la misma vez.

\section{c. ¿Cómo valora un grupo de estudiantes de la} FAREM-Estelí el relato digital como texto pedagógico en su propio quehacer educativo?

Mediante el cuestionaro aplicado se intentó obtener el punto de vista el punto de vista de los estudiantes sobre como valoran el relato digital como texto pedagógico, en sus propios contextos educativos. La totalidad de los estudiantes a quienes se les aplicó el cuestionario afirmó con seguridad que para ellos el relato digital cumple con los requisitos expuestos por Selander y Skjelbred (2004) como texto pedagógico. Doce de ellos expresaron que les gustaría crear sus propios relatos digitales para presentarlos a los compañeros, ya que ellos cuentan con los medios básicos para este tipo de producción digital.

Los estudiantes mencionaron varios beneficios del uso del relato digital. Por ejemplo, para los estudiantes de Lengua y Literatura sus estudiantes pueden mejorar sus habilidades de escritura, lectura y presentación oral. Además, ellos dijeron que sus estudiantes pueden fácilmente investigar sobre un tema, hacer un resumen y presentarlo para el resto de la clase, a través de un relato digital. Dijeron que también que los estudiantes pueden adquirir un grado básico de competencia digital; es decir, el uso de las herramientas básicas de computación para usarlas con propósitos pedagógicos (ver Kress, 2003).

Tocante al punto de vista de los estudiantes de inglés, estos mencionaron que el relato digital puede proveer a sus estudiantes una ayuda al desarrollo de las habilidades básicas del idioma inglés. Estas son el habla, la escritura, la lectura y la escucha (Ver Harmer, 2007). Ellos considearan que en el proceso de producción de un relato digital, sus estudiantes pueden leer mucha información sobre un tema en específico y escribir las 
ideas principales que encuentren. Así mismo, durante el proceso de grabación de su voz estos pueden practicar su pronunciación, dado que antes de grabarla tienen que practicar varias veces. Apuntan también a que mientras el toda la clase observan los relatos digital creados, estos pueden escuchar la pronunciación del autor y mejorar su habilidad de escucha.

Para Wølner y Høiland (2007), Foto Story 3 para Windows es un programa que hace de la producción de relatos digitales "la tarea más fácil en el mundo" ( $p$. 66). Estos dos investigadores hicieron esa afirmación basándose en su contexto noruego. Noruega fue el primer país europeo con un currículo basado en competencias digitales (Søby, 2008). Por tanto, la producción de videos utilizando herramientas digitales allí no supone un desafio tan grande como en otros países.

En un contexto nicaragüense, en contraste, la situación es distinta a la mencionada por Wølner y Høiland (2007). En el taller de Relato Digital implementado en la FAREM-Estelí durante el mes de octubre 2013, se presentaron varios desafíos imporatantes. Entre los obstáculos principales se encuentran: la falta de preparación de los estudiantes en el uso de programas básicos de computación, los frecuentes apagones que sufre la ciudad, el ruido de las calles que también tienen influencia directa en lo que pasa en las aulas de clase de la facultad, así como en el laboratorio, etc. A pesar de las dificultades enfrentadas, los estudiantes que participaron en su estudio pudieron adquirir un cierto grado de competencias digitales, y producir relatos digitales pedagógicos.

\section{CONCLUSIÓN}

Este artículo presentó los términos relato digital y texto pedagógico, con el fin de explorar el potencial del Relato Digital como Texto Pedagógico en un contexto nicaragüense, de acuerdo a las características establecidas por Selander y Skjelbred (2004). Como se ha argumentado en este documento, éste método es fructífero y tiene un gran potencial para ser utilizado en la producción de narrativas personales. Este puede contribuir de varias formas en la educación ya que mediante su aplicación, por poner un ejemplo real, se puede tener la oportunidad de familiarizarse y adiestrarse en el uso de herramientas básicas digitales, a la misma vez que se mejora el arte de contar historias. Para los participantes de este estudio, éste es un método motivador que puede ser utilizado en cualquier país, por ejemplo en Nicaragua, siempre y cuando se tengan los recursos elementales para la producción de relatos personales utilizando medios digitales.

\section{BIBLIOGRAFÍA}

Baltzersen, R. (2012). Digitale fortellinger $i$ skolen. Oslo: Pediapress.

Befring, E. (2007). Forskningsmetoder med etikk og statistikk. Oslo: Det norske samlaget.

Bernard, R. (2008). Digital Storytelling: A Powerful Technology Tool for the 21 st Century Classroom. Theory into Practice (pp. 220-228). Ohio: Rutledge.

Cresswel, J. (2009). Research design: Qualitative, quantitative, and mixed methods approaches. (3rd Ed.). Los Angeles: Sage Publications.

Halliday, M.A.K \& Hasan, R. (1985): Language, context and text: Aspects of language in a socialsemiotic perspective. Oxford: Oxford University Press.

Haug, K., Jamissen, G. \& Ohlmann, C. (2012). Digitalt fortalte historier: Refleksjon for loering. Oslo: Cappelen Damm Akademisk.

Høiland, T. \& Wølner, T. A. (2007). Fra digital ferdighet til kompetanse- Om didaktikk for arbeid med digitale medier i skolen. Oslo: Gyldendal Akademisk.

Kress, G. (2003). Literacy in the New Media Age. New York: Routledge.

Lambert, J. (2010). Digital storytelling cookbook. California: Digital Dinner Press.

Normann, A. (2011). Digital Storytelling in second 
language learning: A qualitative study of

students'reflections on potentials for learning. Master's thesis in didactics for English and foreign language. Trondheim: NTNU Det skapende universitet.

Næss, M. (2006). Digital Historiefortelling. Masteroppgave i medievitenskap institutt for medier og kommunikasjon. Oslo: UiO.

Patton, M. (2002). Qualitative Research and Evaluation Methods (3rd Ed.). CA: Sage.

Real Academia Española (2015). Definición del término 'texto'. Consultado el 14.04.2015, de http://lema.rae.es/drae/srv/search?key=texto

Sadik, A. (2008). Digital storytelling: a meaningful technology-integrated approach for engaged student learning. Education Tech Research.

Selander, S., \& Skjelbred, D. (Red.) (2001). Fokus på pedagogiske tekster. Artikler fra projekter "Valg, vurdering og kvalitetsutvikling av larebøker og andre læremidler." Notat 5/2011. Tønsberg: Høgskolen i Vestfold.

Selander, S. \& Skjelbred D. (2004). Pedagogiske tekster for kommunikasjon og laering. Oslo:
Universitetsforlaget.

Silseth, K., \& Erstad, O. (2012). Minoring the surfaces of the self: Exploring literacy practices of digital storytelling. In S. Østerud, B. Gentilkow, \& E. Skogseth, Litearcy practices in late modernity: Mastering technological and cultural convergences (pp. Chapter 12 (p. 225-244)). Hampton Press.

Søby, M. (2008). Digital competence - From education policy to pedagogy: The Norwegian context. In C. Lankshear, \& N. Knobel, Digital literacies: Concepts, policies and practices. New York, Berlin, Oxford: Peter Lang.

Van Leeuwen, T. (2005). Introducing social semiotics. London: Routledge.

*Nota: Se pueden observar dos relatos digitales producidos por estudiantes de la UNAN-FAREM, Estelí siguiendo los siguientes enlaces.

- Obediencia a tus padres asegura tu futuro: https:// vimeo.com $/ 80143860$

- La Mocuana: https://vimeo.com/84624047 